Revista Iberoamericana

de las Ciencias Sociales y

Humanísticas

ISSN: 2395 - 7972

https://doi.org/10.23913/ricsh.v8i16.181

Artículos Científicos

\title{
Vino nuevo en odres nuevos: Usos y aplicaciones de la imagen y la memoria para la innovación social
}

\begin{abstract}
New Wine in New Wineskins: Uses and Applications of Image and Memory for Social Innovation
\end{abstract}

Vinho novo em odres novos: usos e aplicações de imagem e memória para inovação social

\author{
Iván Gerardo Deance Bravo y Troncoso \\ Benemérita Universidad Autónoma de Puebla, México \\ ivan.deance@correo.buap.mx \\ https://orcid.org/0000-0003-1473-5537 \\ Verónica Vázquez Valdés \\ Benemérita Universidad Autónoma de Puebla, México \\ veronica.vazquezval@correo.buap.mx \\ https://orcid.org/0000-0001-5466-4679
}

\section{Resumen}

Utilizar una técnica de registro visual proveniente del siglo XIX en el siglo XXI en un contexto de investigación social ha sido una tarea que derivó en una estrategia de innovación social para las personas y comunidades con las que hemos trabajado. En un primer apartado se presenta el contexto de la historia de la fotografía química en México. El trabajo pretendió incidir positivamente en el reconocimiento de la memoria y la identidad, individual y colectiva, para la recuperación de espacios en la ciudad contemporánea, así como fortalecer la cohesión social y familiar en grupos minoritarios en el estado de Puebla en México. Dicho trabajo fue realizado con tres grupos sociales: el primero, niños de una casa hogar en condiciones vulnerables; el segundo con estudiantes universitarios de escuela pública, y el tercero con familias de italomexicanos provenientes de una migración del siglo XIX. Mediante estos trabajos se pretendió incidir en la 


\section{Revista Iberoamericana \\ de las Ciencias Sociales y Humanísticas}

ISSN: $2395-7972$

recuperación de espacios urbanos como estrategia de innovación social, a partir de métodos y técnicas de análisis semiótico de la fotografía y la reconstrucción de la historia oral, utilizando a la fotografía química como centro de los trabajos de la investigación. El trabajo tiene la fortaleza de usar recursos de bajo costo para promover la reflexión de procesos colectivos e identitarios vinculados al reconocimiento social y a fortalecer relaciones e interacciones que, estando debilitadas, producen violencia social. Sin embargo, el impacto real y la cuantificación de los logros alcanzados por el proyecto presentan un reto que solo podrá ser abordado en la evaluación continua en los años posteriores a la realización del estudio, y difícilmente se podrá cuantificar el impacto positivo en indicadores numéricos.

Palabras clave: fotografía, imagen, investigación social, memoria, México.

\section{Abstract}

Using a visual registration technique from the 19th century in the 21 st century in a context of social research has been a task that led to a strategy of social innovation for the people and communities with whom we have worked. In a first section we present the context of the history of chemical photography in Mexico. The work aimed to positively influence the recognition of individual and collective memory and identity for the recovery of spaces in the contemporary city as well as strengthening social and family cohesion in minority groups in the state of Puebla in Mexico. This work was carried out with three social groups: the first, children from a home in vulnerable conditions, the second with university students from public schools, and the third with families of Italians from a 19th century migration. Through these works, it was intended to influence the recovery of urban spaces as a strategy of social innovation, based on the methods and techniques of semiotic analysis of photography and the reconstruction of oral history, using chemical photography as the center of the works of the investigation. The work has the strength to use lowcost resources to promote the reflection of collective processes and identities linked to social recognition and strengthen relationships and interactions that, being weakened, produce social violence. However, the real impact and quantification of the achievements of the project present a challenge that can only be addressed in the continuous evaluation in the years after the study is carried out and it will be difficult to quantify the positive impact on numerical indicators.

Keywords: photography, image, social research, memory, Mexico. 
Revista Iberoamericana

de las Ciencias Sociales y

Humanísticas

ISSN: 2395 - 7972

\section{Resumo}

Usar uma técnica de registro visual do século XIX no século XXI em um contexto de pesquisa social tem sido uma tarefa que levou a uma estratégia de inovação social para as pessoas e comunidades com as quais trabalhamos. Numa primeira seção, é apresentado o contexto da história da fotografia química no México. O trabalho teve como objetivo influenciar positivamente o reconhecimento da memória e da identidade, individual e coletiva, para a recuperação de espaços na cidade contemporânea, bem como fortalecer a coesão social e familiar em grupos minoritários no estado de Puebla, no México. Este trabalho foi realizado com três grupos sociais: o primeiro, filhos de um lar em condições vulneráveis; o segundo com estudantes universitários de escolas públicas e o terceiro com famílias de italianos de uma migração do século XIX. Com esses trabalhos, pretendeu-se influenciar a recuperação dos espaços urbanos como estratégia de inovação social, baseada em métodos e técnicas de análise semiótica da fotografia e na reconstrução da história oral, utilizando a fotografia química como centro das obras da pesquisa $\mathrm{O}$ trabalho tem força para utilizar recursos de baixo custo para promover a reflexão de processos coletivos e de identidade ligados ao reconhecimento social e fortalecer relacionamentos e interações que, quando enfraquecidos, produzem violência social. No entanto, o impacto real e a quantificação dos resultados alcançados pelo projeto apresentam um desafio que só pode ser enfrentado na avaliação contínua nos anos seguintes à realização do estudo, e o impacto positivo nos indicadores numéricos dificilmente pode ser quantificado.

Palavras-chave: fotografia, imagem, pesquisa social, memória, México.

Fecha Recepción: Enero 2019

Fecha Aceptación: Junio 2019 
Revista Iberoamericana

de las Ciencias Sociales y

Humanísticas

ISSN: $2395-7972$

\section{Introducción}

Pareciera extraño que en pleno siglo XXI, en la era de la tecnología digital y en los albores del cómputo cuántico, usemos una técnica artesanal creada en el siglo XIX para desarrollar nuestros trabajos de investigación social. La fotografía química ha representado para nosotros una forma de expresión, de arte, pero también una técnica para la investigación social, en el registro de los fenómenos sociales, y una herramienta para la innovación social.

En el cuerpo académico BUAP-CA-318 Imagen, Memoria e Investigación Social de la Benemérita Universidad Autónoma de Puebla (BUAP) se ha utilizado a la fotografía química como medio para el registro de elementos visuales y etnográficos de la vida cotidiana y otros elementos de la vida social de diversas minorías en nuestra región latinoamericana desde el año 2000. Un amplio corpus de diapositivas o positivos fotográficos sobre los usos y costumbres del grupo indígena totonaco en México cubre la mayor parte del trabajo visual para conformar un fondo fotográfico. Sin embargo, posterior a los trabajos etnográficos realizados, la fotografía adquirió un cariz diferente en las reflexiones científicas sociales.

En uno de estos trabajos, por ejemplo, en el cual se le dio la cámara fotográfica a un grupo de diversas generaciones de indígenas totonacos para comprender un poco de su percepción a través del objetivo fotográfico (Vázquez, 2003, 2015a, 2017a), se hizo una aproximación a la cultura visual del grupo étnico, y se logró dilucidar las preferencias estéticas, de encuadre, composición y planos para aplicarlas posteriormente a políticas públicas visuales, con el fin de que tuvieran un impacto más eficiente en términos de los mensajes que se transmiten a las comunidades mencionadas.

A partir de ahí, la participación de los actores sociales en el registro fotográfico se convirtió en una fuente primordial de información y, mejor aún, de coparticipación en la investigación social.

Sin llegar a construir una metodología de "fotografía participativa", a la manera de la investigación acción participativa (IAP), se incluyeron a diversos sujetos en la construcción de conocimiento, junto con los integrantes del equipo de investigación; se sumó su participación en la reflexión de los fenómenos sociales de estudio partiendo de la fotografía química como pretexto.

A partir de tres experiencias de investigación en donde la fotografía química cobra relevancia esencial es que se construyó el presente texto.

En un primer momento se hace una recuperación de la fotografía fisicoquímica en México para contextualizar la importancia de dicha técnica en dicho país y hacer presente los diversos momentos que diferentes generaciones testimoniaron desde el siglo XIX. Posteriormente se 


\section{Revista lberoamericana \\ de las Ciencias Sociales y Humanísticas}

ISSN: 2395 - 7972

abordan los tres casos de interés en donde se utilizó la imagen y la memoria para la innovación social a partir de la fotografía química.

En el primer caso, se usó a la fotografía como una herramienta de reflexión en torno a la pertenencia local, familiar e identitaria en un internado con niños vulnerables. Ahí se les acompañó en la fabricación de cámaras estenopéicas, ${ }^{1}$ así como en el ejercicio de tomas fotográficas con dicha cámara.

En el segundo caso se dotó a un grupo de jóvenes universitarios de técnicas especializadas respecto a la conservación de álbumes familiares para la preservación de la memoria generacional.

En el tercer caso se utilizó los álbumes familiares de los descendientes de inmigrantes del siglo XIX para la recuperación del tejido social a partir del reconocimiento de la pertenencia al pueblo y el grupo humano.

Finalmente se reflexiona sobre los logros y avances que generan el uso de la imagen y la memoria como estrategia para la innovación social en torno a la recuperación de la memoria, el reconocimiento de la participación colectiva y generacional en la recuperación de espacios y la posible reducción de la violencia a partir del fortalecimiento de procesos identitarios y de pertenencia social.

\section{Un recorrido histórico de la fotografía en México}

La fotografía en México puede ser abordada desde dos vertientes. Una a partir de la historia de los procesos sociales y políticos de México. Y otra en torno a los procesos químicos de la fotografía. En este apartado, haciendo un tejido entre ambas, se presenta un breve recorrido histórico de la fotografía en México, y, a su vez, se explican los procesos químicos que esta técnica ha presentado.

El periódico El Cosmopolita del 15 de enero de 1840 (citado en Debroise, 2005, p. 36) incluye entre sus páginas información respecto a la incorporación del daguerrotipo² en México: ahí

\footnotetext{
${ }^{1} \mathrm{Si}$ bien más adelante en el texto se explica a detalle la técnica de la cámara estenopeica (ver nota 12) por el momento basta con mencionar que se trata de una técnica fotográfica histórica que se realiza sin el uso de lentes u objetivos a partir de una cámara obscura con un pequeño orificio llamada estenopo.

${ }^{2}$ El daguerrotipo era una placa rígida de cobre que se procesaba químicamente para dejar en ella una imagen positiva: primero se pulía la placa y se cubría con plata y se sensibilizaba con vapores de yodo. Después de exponer la foto en la cámara, se revelaba con vapores de mercurio y se fijaba con hiposulfito de sodio. El resultado era una imagen única y positiva. El proceso de la daguerrotipia era complicado y costoso, y además requería un estudio, por lo que casi no se utilizó para panoramas, sino para retratos. Estos retratos en daguerrotipo solo estuvieron al alcance de las clases altas (González, 2007, p. 7). El daguerrotipo fue inventado y patentado en 1839 por Louis-Jacques-Mandé Daguerre, quien retomó y prácticamente se apropió del trabajo pionero realizado por Nicéphore Niépce (Valdez, 2001, p. 10).
} 


\section{Revista Iberoamericana}

de las Ciencias Sociales y Humanísticas

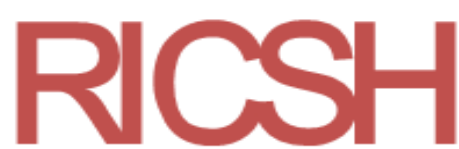

ISSN: $2395-7972$

el francés Louis Prélier se revela como protagonista, pues, en diciembre de 1839, desembarcó en el puerto de Veracruz con dicho aparato. Prélier realizó "una demostración pública registrando el puerto de Veracruz, poco después el Palacio de Plazas de Armas, los edificios principales de esta con sus portales, parte de la calle real, el Convento de San Francisco, la bahía y el Castillo de Ulúa" (El Cosmopolita, 15 de enero de 1840; citado en Debroise, 2005, p. 36). En pocos días, "el 26 de enero, Prélier repitió este mismo ejercicio en la plaza mayor de la ciudad de México y la catedral." (El Cosmopolita, 29 de enero de 1840; citado en Debroise, 2005, p. 36).

Villela (1998, p. 108) señala que la fotografía etnológica llegó a México el año de 1841 con el viajero alemán Emanuel Von Friedrichsthal, quien, por medio de un aparato fotográfico, tomó vistas de las zonas arqueológicas de Uxmal, Chichén Itzá e Izamal en la península de Yucatán. Entre los exploradores pioneros de la fotografía y verdaderos precursores de la arqueología y etnografía figuran personajes como John L. Stephens y Frederick Catherwood. Ambos llegaron a Yucatán en ese mismo año de 1841.

Posteriormente, llegó el químico Théodore Tiffereau, quien "hizo varios retratos que dan una idea del tipo mexicano" (Villela, 1998, p. 110; citado en Roussin, 1993, p. 99). Tiffereau es considerado como uno de los primeros daguerrotipistas en retratar indígenas; estuvo en México de 1842 a 1847. Otro pionero de la foto etnográfica es Teoberto Maler. Este arqueólogo llegó a "México junto con la primera compañía de cadetes de Maximiliano, realizó una serie fotográfica sobre la zona arqueológica de Mitla" (Villela, 1998, p. 113).

Se puede decir que todos los daguerrotipistas que trabajaron en México entre 1840 y 1855 fueron extranjeros, sobre todo franceses y estadounidenses. Estos fotógrafos viajeros recorrieron el territorio nacional en busca de motivos arquitectónicos, paisajes urbanos y monumentos arqueológicos para describir a México.

Laura González (2007) señala: 


\section{Revista Iberoamericana de las Ciencias Sociales y Humanísticas}

Como medio de representación, la daguerrotipia era una técnica muy precisa y por ello insuperable, pero no se podían hacer copias como con las técnicas negativopositivas: el calotipo ${ }^{3}$ o papel salado ${ }^{4}$. Este problema se resolvió con negativos de cristal, de colodión ${ }^{5}$ y albúmina ${ }^{6}$, que sustituyeron a la daguerrotipia hacia mediados de la década de 1850 (p. 7).

Asimismo, González (2007) indica que el colodión y la albúmina tenían muchas ventajas: eran precisos y reproducibles, se caracterizaban por su reproducción de fotografías múltiples sobre retratos, esto era mediante lentes múltiples donde se obtenían hasta doce tarjetas de visita en una misma toma. Y por ser fáciles y económicos de fabricar, su consumo se extendió a las clases medias (González, 2007, p. 8).

El arqueólogo Désiré Charnay, considerado una figura fundamental en el desarrollo de la fotografía y la arqueología, realizó trabajo fotográfico en "Mitla, Palenque, Izamal, Chichén Itzá, Uxmal" (Villela, 1998, p. 111). "Entre 1858 y 1861, en el que además de los panoramas urbanos, realizó los colodiones del álbum Ciudades y ruinas americanas" (González, 2007, p. 16).

\footnotetext{
${ }^{3}$ Proceso fotográfico con negativo en papel, descubierto por William Henry Fox Talbot en 1840 y patentado en 1841. Es considerado el antecesor directo de la fotografía moderna, ya que fue el primer proceso que utilizó el sistema negativo-positivo (González, 2007, p. 10).

${ }^{4}$ Primer tipo de impresión fotográfica, realizado por contacto generalmente con negativos de papel (calotipos) y ocasionalmente con placas negativas de colodión sobre vidrio. Este proceso fotográfico fue descubierto por Henry Fox Talbot en 1840. Las impresiones en papel salado fueron utilizadas hasta mediados de la década de 1860, aunque su producción fue en descenso a partir de 1851, fecha en la cual surgen las impresiones en albúmina como alternativa técnica. Una característica de las impresiones sobre papel salados es que no dan detalles finos, debido a los efectos de la luz esparcida en las fibras de papel (González, 2007, p. 22).

${ }^{5}$ Coloide aplicado en fotografía en 1848 por Gustave Le Gray; posteriormente Frederick Scott Archer, en 1851, retomó la experiencia y permaneció el método. Este compuesto se empleaba en la elaboración de negativos y de positivos; existían dos variantes conocidas como colodión húmedo y colodión seco. El húmedo fue utilizado en los procesos de ambrotipia, ferrotipia y negativos con soporte de vidrio, mientras que el colodión seco en la elaboración de impresiones de papel y, dependiendo del tipo de superficie que proporcionaba a las impresiones, se le conocía como colodión secomate y colodión seco-brillante. Estas impresiones se les denomina en la actualidad impresiones de colodión, y pertenecen al grupo de papeles denominados de autorrevelado (printing-out papers). En ellas la imagen se obtenía sin la necesidad de un revelado químico (González, 2007, p. 11).

${ }^{6}$ Coloide empleado como sustrato fotográfico extraído de la clara de huevo. La albúmina fue utilizada en el siglo XIX para producir impresiones fotográficas en papel, comúnmente llamadas impresiones de albúmina, así como para la elaboración de negativos con soporte de vidrio (González, 2007, p. 8).
} 


\section{Revista Iberoamericana \\ de las Ciencias Sociales y Humanísticas}

ISSN: $2395-7972$

En México, de 1860 a 1890, los fotógrafos de estudio anunciaban los daguerrotipos, ambrotipos $^{7}$, ferrotipos ${ }^{8}$ y copias sobre papel con el nombre genérico de daguerrotipos. Ante dicha situación, Rosa Casanova (2005) indica lo siguiente:

El territorio mexicano quedó marcado por la presencia de efímeros estudios improvisados por los daguerrotipistas y ambrotipistas que recorrieron el país, estableciendo un itinerario regido por las fiestas que, afianzadas en el pasado virreinal, conjugaban ritualidades religiosas y vida cívica a través de ferias y conmemoraciones patrias que aseguraban la congregación de un gran número de personas y hacían previsible la venta de retrato, además, a través del retrato, el oficio del fotógrafo se convierte en una fuente estable de ingreso (p. 7).

Debroise (2005) argumenta que entre 1864 y 1867 existió el primer boom de la fotografía en México, debido a la inauguración de más de 20 estudios dedicados a la producción de tarjetas de visita y de tarjetas “imperiales” en la ciudad de México (p. 53).

Aunado a ello, Debroise (2005) precisa lo puesto a continuación:

Entre otros comerciantes europeos dedicados a actividades suntuarias - sastres, hoteleros, pasteleros y cocineros- llegaron pues los fotógrafos. Los franceses: Amiel, Mérille y François Aubert, seguidos por Jean Baptiste Prévost, Adrien Cordiglia y Auguste Péraire; los españoles: Julio de María y Campo, José Pedebiella y J. B. Parés (asociado en Veracruz con una tal Ventura); los estadounidenses: J. Tomwang, Vaughan y Compañía y John Tutrig, quien también trabajó en México durante la Intervención francesa. En forma paralela, los mexicanos: Francisco Montes de Oca, Lauro Limón, Andrés Martínez, Luis Campa, Antíoco Cruces, Agustín Velasco, Joaquín y Maximino Polo, Luis Veraza, Manuel Rizo y Julio Valleto (p. 53).

Y volviendo a Rosa Casanova (2005):

\footnotetext{
7 Proceso realizado con colodión húmedo, el cual produce una imagen positiva directa sobre una placa de vidrio; también es conocido como positivo al colodión o daguerrotipo de los pobres. Este proceso fue patentado por James Ambrose Cutting en 1854 (González, 2007, pp. 8-9).

8 También llamado tintype en Estados Unidos, es un proceso fotográfico derivado del ambrotipo, sólo que el soporte es una placa de fierro. Su descubrimiento se atribuye al francés Adolphe Alexander Martin en 1852, pero hay quienes aseguran que fue descubierto por Hannibal L. Smith en 1856 (González, 2007, p. 16).
} 


\section{Revista Iberoamericana de las Ciencias Sociales y Humanísticas}

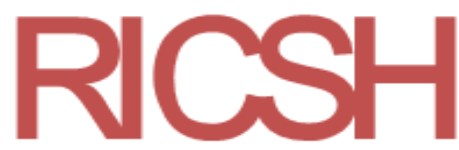

ISSN: $2395-7972$

El retrato fotográfico sirvió de base para el estudio e identificación de comportamientos e individuos y se convirtió en un mecanismo coadyuvante en el control de la delincuencia que creció desmesuradamente con la inestabilidad de los mismos gobiernos y la incertidumbre social y económica (p. 9).

Por otra parte, Laura González (2007) menciona que:

Para mediados de la década de 1880 se difundió el uso de placas "secas" de gelatina" que ahorraban el trabajo de sensibilizar la placa antes de la toma. Por su facilidad de uso, las placas secas se emplearon para trabajos en exteriores, como registro de obras durante el porfiriato. Su alta fotosensibilidad permitió la captura "instantánea" de escenas en movimiento, hecho que resultó indispensable durante la Revolución. Además, al revelarse de modo especial, producían transparencias que podían proyectarse en aparatos iluminados con velas. Sus temas incluían vistas turísticas, monumentos arquitectónicos o espectáculos populares, como la fiesta del Centenario de la Independencia (p. 9).

Debroise (2005) indica que los fotógrafos o los dueños de empresas fotográficas proponían a su clientela diversos atractivos, por ejemplo, múltiples formas de utilizar o de portar consigo los retratos, como los conocidos relicarios de plata u oro, que por lo regular solían colocarse en la tapa de una cigarrera, en una pulsera o inclusive en un anillo. Otros ofrecían retratos impresos en soportes como tela, hule, madera, platos, bandejas y tazas de porcelana (Debroise, 2005, p. 59).

Con respecto a la fotografía indigenista ${ }^{10}$, Del Castillo (2005) comenta:

El régimen porfiriato amplió y profundizó una revisión de la historia mexicana, que trazó una relectura de los objetos prehispánicos, convertidos por el arte de la educación cívica en símbolos patrios, y los exhibió pulcramente en los anaqueles del Museo Nacional de la Ciudad de México (p. 63).

\footnotetext{
${ }^{9}$ Este tipo de placa negativa proporcionaba buena definición tonal y se empleaba para diferentes tipos de papeles fotográficos, tanto de albúmina como de sustrato de plata/gelatina, incluida para imágenes en colodión mate. Con su uso se obtenía gran variedad de impresiones y de buena calidad. Parte de la producción fotográfica de finales del siglo XIX y de las tres primeras décadas del XX se realizaba a partir de este tipo de negativos. La distribución homogénea de la emulsión sobre la placa de vidrio es básica para diferenciarla de las placas de colodión húmedo: por otro lado, los tonos blanco y negro de la imagen son continuos y no existen variaciones tonales, salvo las producidas por un proceso de sulfuración, resultantes de un deficiente o inadecuado proceso de revelado químico (González, 2007, p. 24).

10 “Es tan estandarizada, que la discursividad del fotógrafo individual manifiesta solo la selección de un tipo discursivo con pequeñas inflexiones personales. (...) La diversidad discursiva que encuentro en la fotografía indígena tiene que ver con sus características estético-políticas que se construyen según (...) en el campo científico, el comercial, el artístico y el escolar" (Corona, 2007, p. 80).
} 


\section{Revista Iberoamericana \\ de las Ciencias Sociales y Humanísticas}

ISSN: $2395-7972$

La fotografía fue utilizada en un sentido documental con la finalidad de recrear un inventario de los distintos grupos étnicos repartidos por el territorio del país.

Villela (1998) señala que "la fotografía etnográfica" encontró en Lumholtz uno de sus primeros exponentes con clara orientación técnica y científica. El proceso que siguió es intermedio entre la mera ilustración y el método de análisis" (p. 114). Sin embargo, Del Castillo (2005) enfatiza sobre Carl Lumholtz lo siguiente:

Realizó seis viajes de estudio entre 1890 y 1910, financiados por el Museo Americano de Historia Natural de la ciudad de Nueva York, y estudió algunos de los grupos indígenas que habitaban en el noroeste mexicano, permaneciendo entre ellos largas temporadas, durante las cuales tomó miles de fotografías sobre placas de vidrio con una cámara de 8 x 10 pulgadas (p. 64).

Canales (2005) argumenta que en 1896 se introdujeron las rotativas, linotipos y la técnica de impresión en medio tono, lo cual impulsó la modernización de la prensa, y empezaron a aparecer, casi siempre sin crédito, las imágenes de varios periodistas. En este mismo año, León Diguet emprendió en el noroeste del país una misión con fines etnográficos (Canales, 2005, p. 273). Del Castillo (2005, p. 63) aclara que su estudio central se refirió al grupo de los huicholes, aunque también abarcó a coras, yaquis, tepehuas, otomíes, cochimíes y nahuas, y rescató aspectos de la flora y la fauna, que formaban parte de sus intereses.

Por otra parte, González (2007, p. 32) indica que antes de la Revolución mexicana existían imágenes de guerra, tales como retratos de combatientes y sus campamentos, o simplemente vistas panorámicas de los campos de batalla devastados, y sobre todo de cadáveres abandonados. "El surgimiento de la violencia revolucionaria en 1910 terminó con el sueño de perpetuidad del gobierno porfiriano. Los fotógrafos salieron a las calles a registrar los nuevos hechos y acontecimientos, enfrentando retos técnicos y tareas cada vez más complejas" (Del Castillo, 2005, p.72).

En fin, González (2007) indica que:

\footnotetext{
${ }^{11}$ Nombrada también como fotografía antropológica. "Es la realizada por antropólogos, como medio de investigación concretando en una metodología específica. (...) Habría que empezar por situar la fotografía antropológica como explica José Muñoz 'en un lugar propio que sería el de aproximación / interpretación / explicación de la realidad desde una perspectiva científica, entendiendo en este caso científica como propia de las ciencias sociales y, más concretamente, de la etnografía"' (Sánchez, 2006, p. 54).

Al igual que en la nueva etnología, lo que valida a los fotógrafos es ser testigos. Su certificado de autenticidad es haber estado allí. (Ramírez, 2001, p. 119)
} 
Revista Iberoamericana

de las Ciencias Sociales y

Humanísticas

ISSN: 2395 - 7972

A veces profesional, a veces aficionado casual, el fotógrafo fue un protagonista central del conflicto armado. De modo individual o acompañado por otros colegas, el fotógrafo documentó los acontecimientos más significativos de la Revolución, al construir una imagen reconocible de ésta y de sus caudillos (p. 32).

De hecho, la fotografía de la Revolución, según González (2007):

No solo hace visible el México real, complejo y contradictorio, también define una serie de imágenes representativas que los gobiernos posrevolucionarios utilizaron en su proyecto nacionalista. (...) Por su capacidad de registrar cómo y dónde sucedían los acontecimientos, la fotografía de la Revolución mexicana pretendía ser una documentación "objetiva”, y por ello, muchas fotografías son anónimas: lo importante era hacer constar el suceso y no quien lo había documentado. Por lo general, la firma de las imágenes tenía razones de comercialización y no la valoración de la autoría personal (pp. 33-34).

Rebeca Monroy (2005) enfatiza que el periodo posrevolucionario:

Marcó lineamientos importantes para la fotografía mexicana, hubo continuidades, rupturas y transformaciones en sus formas de realización, así como innovaciones en sus temas y géneros gráficos. (...) Se mejoraron los materiales fotosensibles de las placas y películas para la cámara. Las lentes presentaron menos aberraciones ópticas y tuvieron una mayor luminosidad. Por su parte, las cámaras fueron más ligeras y de un manejo más accesible que sus antecesoras; los flashes fueron menos aparatosos permitiendo tomas más rápidas en interiores o en escasas condiciones de luz, donde el tripié también era muy utilizado (p. 119).

Ante el avance del movimiento revolucionario, muchas mujeres empezaron a hacerse cargo de los establecimientos fotográficos familiares que no podían ser atendidos por los varones durante el año de 1914 (Canales, 2005, p. 275).

Alfonso Morales (2005) señala que la fotografía hecha en México entre 1940 y 1970:

Amplió notablemente su catálogo de ofertas y servicios, a la vez que siguió batallando por su legitimidad artística. (...) En el curso de aquellas tres décadas, la fotografía alcanzó a los públicos masivos no solo porque cámaras y materiales tuvieron precios más accesibles sino, sobre todo, a causa de su desdoblamiento en otros medios de producción visual. En los diarios fue información, ilustración o 
Revista Iberoamericana

de las Ciencias Sociales y

Humanísticas

ISSN: $2395-7972$

simple relleno. Las artes gráficas la divulgaron como estampa, postal, cartel o etiqueta (pp. 182-183).

Ahora bien, González (2007) apunta que la fotografía actual se distingue por su carácter construido, escenográfico o teatral, que además se acentúa con el uso del color. A este respecto, se debe reconocer la influencia de Manuel Álvarez Bravo. Si bien es mejor conocido por sus fotos “surrealistas” en blanco y negro, Álvarez Bravo también fue un fotógrafo de color extraordinario; sus experimentos de los años 60 introdujeron un concepto de color diferente al folclórico con que se asociaba México. Ya en los años 80 el color, como propuesta estética, reapareció con autores como Lourdes Grobet, Rubén Ortiz, Salvador Lutteroth, Vicente Guijosa y Lourdes Almeida, entre otros. Cercanas a las formas y conceptos de los medios masivos, las propuestas de estos fotógrafos promovieron nuevos vocabularios en la fotografía mexicana que se afirmarían en la posmodernidad (González, 2007, p. 43).

Finalmente, mientras que la fotografía muestra su fabricación gracias a la tecnología digital, la sociedad misma, en sus imágenes representativas, exhibe sus procesos de construcción. Es decir:

Construidas mediante el reciclaje de fragmentos de documentos de identidad de personas con orígenes culturales y ciudadanías diversas, esas imágenes proponen una comparación interesante: la de la compleja construcción de la identidad contemporánea y la de la fotografía actual, basada en el montaje y la fabricación (González, 2007, p. 45).

\section{Métodos y aplicaciones de la imagen y la memoria para la innovación social}

En este trabajo se utilizó la semiótica de la fotografía para describir las fotografías utilizadas en los tres grupos con los que se trabajó (el primero, niños de un internado en condiciones vulnerables, el segundo con estudiantes universitarios de escuela pública y el tercero con familias de italomexicanos provenientes de una migración del siglo XIX).

Cabe señalar que la semiótica de la fotografía se deriva de la semiótica de la imagen. En este sentido, la fotografía pertenece a toda una categoría de signos que el filósofo y semiótico norteamericano Charles Sanders Peirce llamó index por oposición a ícono y a símbolo. Además, definió al signo fotográfico a partir de su relación con el objeto (la segundidad del signo): por un lado como un ícono, por otro como índice. Así, las fotos son, en cierto modo, exactamente como los objetos que representan y, por lo tanto, icónicas. Por otro lado, mantienen una ligazón física 


\section{Revista Iberoamericana \\ de las Ciencias Sociales y Humanísticas}

ISSN: $2395-7972$

con su objeto, lo que las vuelve indiciales, porque la imagen fotográfica está obligada físicamente a corresponder punto por punto con la naturaleza. Otro aspecto de la foto que Peirce interpreta semióticamente es la posibilidad de su reproducción técnica.

En consecuencia, Peirce (1974) afirma que un signo es una cosa que nos permite conocer alguna cosa más. "El signo, así, no es la simple representación de una realidad, sino que, gracias al intérprete, es también la posibilidad implícita de decir lo otro" (Pericot, 2002, p. 22). Ahora bien, Morris (1985) distingue en la semiosis tres dimensiones: sintaxis, semántica y pragmática. La sintaxis es considerada como el estudio de las relaciones sintácticas de los signos entre sí haciendo abstracción de las relaciones de los signos con los objetos o con los intérpretes. La semántica se ocupa de la relación de los signos con sus designata y, por ello, con los objetos que pueden denotar o que, de hecho, denotan. La pragmática es la relación de los signos con sus intérpretes.

Para Morris (1985):

La sintaxis habla de las reglas de formación y transformación, pero las reglas son modos posibles de conducta e implican la noción de intérprete; "regla" es, por consiguiente, un término pragmático. La semántica alude explícitamente solo a los signos como objetos o situaciones que designan, pero no existe una relación de ese tipo sin reglas de uso semántico, y esto supone de nuevo, implícitamente, la noción de intérprete. La pragmática solo se ocupa directamente de los signos interpretados, pero "intérprete" e "interpretante" no pueden definirse sin usar "vehículo sígnico" y "designatum", de forma que todos estos términos son términos estrictamente semióticos. (p. 101).

Por ende, en este trabajo fueron necesarias y útiles estas tres dimensiones de la semiosis. La sintaxis relacionada con la percepción, la semántica relacionada con el contenido visual y la pragmática en relación con el texto y su contexto.

\section{Imagen y memoria con niños}

Cuando se piensa en los más pequeños de la sociedad, se suele imaginar caritas sonrientes de camino a la escuela en una familia tradicional, que a la tarde les recibe con ansia para hacer los deberes y quizá comer juntos. Sin embargo, la realidad en nuestra región latinoamericana está plagada de situaciones que antes eran consideradas atípicas: los niños y niñas se encuentran en condiciones desfavorables rodeados de elementos que producen, o son producto, de la 


\section{Revista Iberoamericana \\ de las Ciencias Sociales y Humanísticas}

ISSN: $2395-7972$

desintegración familiar, contextos de violencia y en diversos casos de trabajo forzado y explotación infantil.

Para el caso de trabajo con niños, la dinámica del uso de la fotografía química se llevó a cabo en el Internado Julian Hinojosa, con un grupo de niños de primaria, hijos de sexoservidoras de la ciudad de Puebla, México. Estos niños estudian de lunes a viernes y solo los fines de semana conviven con sus madres, debido a que ellas laboran durante toda la semana. El objetivo del taller proporcionado a este grupo de niños fue enseñarles la importancia del uso de la imagen a partir de la cámara estenopeica para registrar parte de su vida diaria.

Cabe mencionar que la fotografía estenopeica es aquella que se realiza sin el uso de lentes u objetivos. Básicamente consiste en una cámara oscura con un pequeño agujero llamado estenopo, por el que entran los rayos luminosos que incidirán sobre el papel fotosensible o en la película

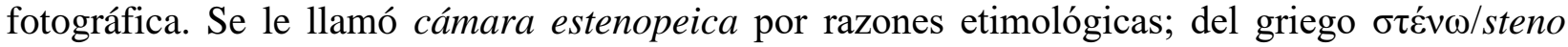
'estrecho', ỏ formar una imagen más o menos nítida en el papel o película fotográfica (imagen olvidada, s. f.).

En nuestro caso, las cámaras estenopeicas se elaboraron a mano, de forma artesanal. Y para su fabricación utilizamos los siguientes materiales: una caja de cartón proveniente de un paquete de cerillos, un rollo de película fotográfica, un magazín vacío de película fotográfica, una laminilla de aluminio, la pieza que se ocupa para abrir las latas de bebidas carbonatadas y carretes de cinta de aislar. Como herramientas de armado utilizamos pinzas de punta fina, navajas de corte fino, papel lija fino, tijeras y agujas.

Para el agujero estenopeico se hizo una perforación con una aguja de cocer en una hoja delgada de aluminio lijado, la cual se montó y adhirió a un marco recortado en la pared frontal de la caja de cartón. En la parte contraria al orificio estenopeico, estaba la película fotográfica. Como obturador se usó una lámina de un material opaco, que se abría y cerraba de forma manual, como una ventana, exponiendo la película a la luz durante los segundos deseados. La película se recorría utilizando la palanca de aluminio que viene en las bebidas carbonatadas; se deformó con pinzas de punta para que pudiera embonar en el orificio de recorrido del magazín de fotografía. Para la exposición fotográfica se utilizó película a color ISO 400, con miras a favorecer la sensibilidad de la luz y aumentar la probabilidad de éxito en las tomas fotográficas.

Para el desarrollo del trabajo general se realizaron los siguientes pasos: 


\section{Revista Iberoamericana de las Ciencias Sociales y Humanísticas}

ISSN: 2395 - 7972

a) Se contactó a las autoridades escolares y administrativas del internado para explicarles la actividad del taller de elaboración de cámaras estenopéicas con elementos de bajo costo y obtener como producto una narración visual de la vida cotidiana de cada menor participante.

b) Se diseñó el taller acorde a las indicaciones y particularidades de los menores que nos fueron indicadas por la especialista psicológica del internado; algunas de las indicaciones se basaban en el carácter de tal niño, la atención especial que requería alguna pequeña o la impaciencia de otro más. Adicionalmente se nos contextualizó de la situación familiar de los niños, así como las complejidades de inserción social de varios de ellos y ellas.

c) Se prepararon los materiales necesarios para que los pequeños tuvieran que realizar en el menor número de pasos posibles en la fabricación de la cámara.

d) Se diseñó la explicación de la técnica de fotografía química, el fenómeno fisicoquímico involucrado, así como algunos elementos del proceso interno de la cámara y el uso de la misma, todo con explicaciones cortas y acordes a su edad.

e) Se realizó la aplicación del taller de elaboración con las especificaciones antes mencionadas, así como la realización de las primeras tomas y su registro escrito correspondiente para cada exposición, y se concluyó con las indicaciones necesarias para que pudieran registrar algunas actividades de su vida cotidiana con precisión, en nuestra ausencia.

Figura 1. Enseñando a elaborar la cámara estenopeica en el Internado Julian Hinojosa

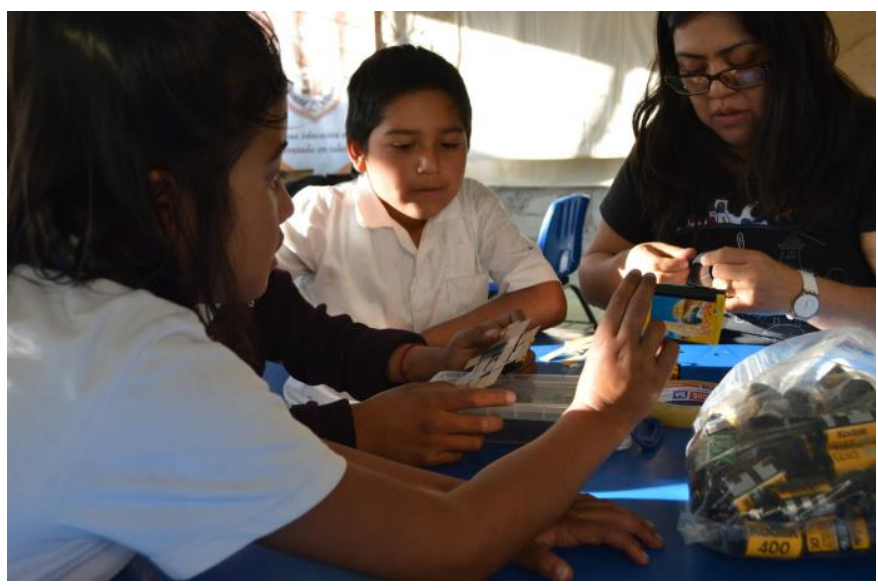

Fuente: Vázquez (2017b) 
Revista Iberoamericana

de las Ciencias Sociales y

Humanísticas

ISSN: $2395-7972$

Figura 2. Rostro de una niña elaborando una cámara estenopeica

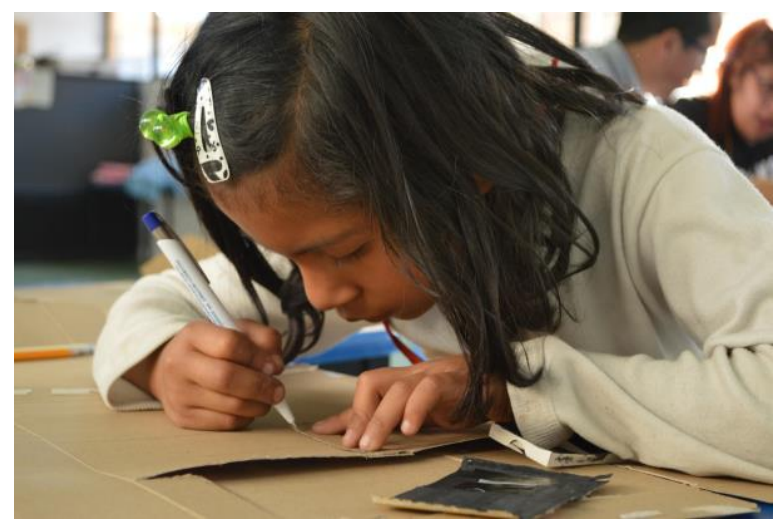

Fuente: Vázquez (2017c)

Durante el taller de elaboración de la cámara surgieron un sinfín de vicisitudes que no se tenían contempladas, algunas relacionadas con la propia condición de ser menor y otras más con la condición generacional de la preferencia por la inmediatez.

En el terreno de lo práctico, las manos pequeñas de los menores rompían o sobretrabajaban con frecuencia alguna parte del proceso, tal y como en el momento de hacer el orificio estenopeico o lijar la laminilla de aluminio en donde se encuentra el mismo. De igual forma, el sellar la película fotográfica con la cinta adhesiva aislante tuvo diversas dificultades, las cuales pudimos corroborar al identificar fugas de luz al momento del revelado.

En el terreno de lo cognitivo, la mayor dificultad se presentó al hacer reflexionar a los pequeños sobre el proceso de obtención de la imagen. Al momento de que ellos realizaron la primera exposición, preguntaban invariablemente: Y ahora, ¿dónde se ve la foto?

A partir de lo anterior, los niños y niñas tuvieron la oportunidad de narrar a través de la cámara estenopeica la vida que tienen en un fin de semana con sus madres. Al analizar semióticamente las fotografías realizadas por cada niño o niña, se observó que sintácticamente registraron los espacios de sus casas en planos generales, y cuando retrataban a su mamá buscaban siempre el primer plano. Semánticamente se puede decir que registraron la vida cotidiana con sus madres en un fin de semana con las siguientes actividades: comiendo y haciendo labores de casa. Pragmáticamente, el uso de la cámara estenopeica fue un vínculo entre cada niño y niña con su madre, además una actividad de convivencia y acercamiento familiar. Al final del texto se presentan las conclusiones generales del ejercicio. 


\section{Imagen y memoria con jóvenes}

El segundo grupo con el que se trabajó fue con estudiantes universitarios en Puebla, México. A ellos se les enseñó la importancia de la imagen fotográfica como patrimonio de la humanidad, basándonos en las recomendaciones de la Organización de las Naciones Unidas para la Educación, la Ciencia y la Cultura [Unesco] (1992, 2003), utilizando como centro de la reflexión las fotografías de sus propios acervos fotográficos familiares, así como algunas técnicas de identificación de materiales, conservación y preservación fotográfica.

El trabajo realizado requirió los siguientes pasos:

a) Presentación del taller de preservación fotográfica y los objetivos del mismo a las autoridades académicas.

b) Planeación del taller de preservación fotográfica acorde a los conocimientos propios de estudiantes universitarios. Cabe mencionar que los estudiantes pertenecían a la Lic. en Ciencias de la Comunicación y contaban con conocimientos previos de fotografía digital.

c) Elaboración de paquetes de intervención y conservación fotográfica, así como las explicaciones para el tratamiento de las fotografías. En este paso también se hizo la elaboración de los contenidos históricos, origen de la fotografía química y los procesos fisicoquímicos propios de dicha técnica, así como las etapas de apropiación y uso de la fotografía, desde su origen en el siglo XIX y hasta finales del siglo XX, para contextualizar las diferentes técnicas fotográficas que intervendrían en sus acervos fotográficos familiares.

d) Aplicación del taller, comenzando con la valoración del estado de conservación de cada acervo familiar para evitar daños irreparables provocados por el taller.

e) Enseñanza posterior al taller sobre las formas internacionales de catalogación y la aplicación a sus propios acervos de la "Norma Mexicana Nmx-r-069-scfi-2016”, así como la “Catalogación Mínima de Objetos Digitales (CMOD)" del Laboratorio Universitario de Imagen y Memoria (LUIM) de la BUAP. 
Revista Iberoamericana

de las Ciencias Sociales y

Humanísticas

ISSN: 2395 - 7972

Figura 3. Estudiantes de la Lic. en Comunicación en el Seminario de Fotografía e Imagen para la Investigación Social

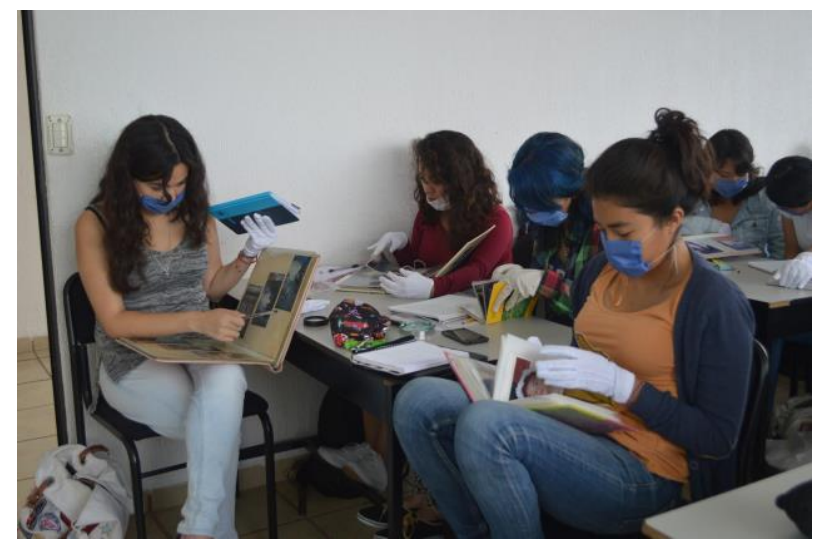

Fuente: Vázquez (2015b)

Figura 4. Estudiantes de la Lic. en Comunicación en el Seminario de Fotografía e Imagen para la Investigación Social

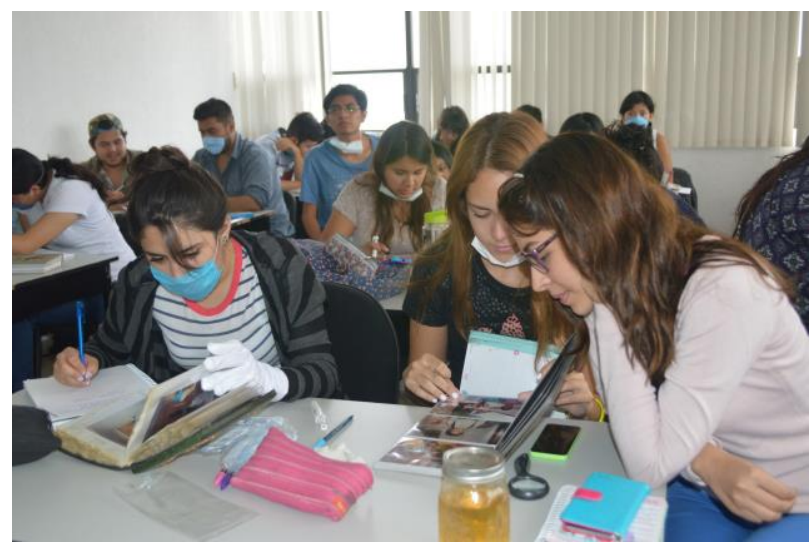

Fuente: Vázquez (2015c)

Realizar el taller de preservación fotográfica con jóvenes universitarios ubicados dentro de la generación milenial resultó un trabajo altamente satisfactorio y emotivo.

A sabiendas del prejuicio presente sobre todo en la población adulta respecto a que los jóvenes desarrollan "escasos procesos de lectura crítica" y otros elementos de crítica social que apuntan hacia la ausencia de conocimiento sobre contextos internacionales y socioculturales adversos que vivimos, el taller tuvo la meta de generar conciencia y reflexión en torno a la importancia de la preservación fotográfica para la recuperación de la memoria y la continuidad cultural, y al mismo tiempo el objetivo de aportarles herramientas prácticas para el tratamiento de sus acervos familiares, con un cuidado cercano al tratamiento que haría un profesional de la conservación. 


\section{Revista Iberoamericana de las Ciencias Sociales y Humanísticas}

ISSN: $2395-7972$

Durante el taller se revisaron elementos propios de las diferentes técnicas que presentaban los acervos de los estudiantes, al igual que diferentes condiciones de conservación y los peligros que existen en torno a los factores que suponen deterioro para los objetos fotográficos. Riesgos que van desde condiciones de acidez y temperatura hasta cierta fauna nociva fueron exponiéndose a lo largo del taller.

Al valorar el estado de conservación de sus propias fotografías y la catalogación de estas se logró fortalecer la identidad de cada uno de los estudiantes. Sintácticamente, las fotografías con las que decidieron trabajar fue con planos generales; semánticamente escogieron la temática de la festividad de sus cumpleaños, y pragmáticamente reafirmaron la organización y participación familiar en los cumpleaños de cada uno de ellos. Asimismo, se reafirmó la identidad de cada estudiante al recordar los valores familiares, así como la situación económica familiar que se vivía en esos momentos. Las dudas al respecto fueron aclaradas mediante sus padres.

Para no ahondar en lo técnico, se resaltarán los elementos de aprendizaje que se rebasaron en cuanto a las perspectivas sobre el taller.

Al momento de la revisión de materiales, una estudiante rompió en llanto, lo que sin duda desconcertó el ejercicio docente, y otros más se mostraron en condiciones emotivas singulares. Al percatarnos de la primera estudiante mencionada, se trató de calmarla y atender su aparente crisis.

Una vez que pudo recuperar el semblante, contó la historia de la separación de sus padres a una temprana edad y cómo durante el resto de años su mamá la convenció de que su padre se fue "porque no la quería", "nunca la quiso" y que "las abandonó sin alguna explicación”. Teniendo de fondo el rencor y el odio con el que una niña puede crecer ante semejante explicación recurrente a lo largo de los años, separó de su soporte original un gran retrato suyo capturado durante su infancia primigenia donde se miraba una mano que la sostenía. Al voltear la fotografía, la estudiante encontró una dedicatoria escrita a mano, con ciertas marcas de tinta corrida: su padre le decía lo mucho que la amaba y cómo ella había sido la ilusión más grande en su vida y le explicaba que tenía que dejar el país por diversas circunstancias políticas y de peligro para su familia; que no podía llevarla con él pero que "la llevaría en su corazón todos los días del resto de su vida y aun después de su muerte". Una vez explicado este asunto, ella se sumió en un profundo llanto mezclado de ilusión, risas nerviosas y una sensación que describió como liberadora; como si un gran costal de piedras la hubiera acompañado durante todos esos años y en ese momento le hubieran despojado de él. 


\section{Revista Iberoamericana \\ de las Ciencias Sociales y \\ Humanísticas}

ISSN: $2395-7972$

De este caso no trataremos más, pero derivado del taller varios estudiantes decidieron realizar sus tesis de grado, basando sus trabajos en la fotografía y la memoria como fuente principal de investigación. Casos como el de una estudiante que a partir de su acervo familiar rastreó la vida de su madre como corredora olímpica y realizó una investigación basada en hemerografía histórica y entrevistas a exentrenadores y exparejas de su mamá. O el caso de otro estudiante que desarrolló su investigación a partir de fotografías instantáneas, y logró recrear los espacios con la misma técnica en su ciudad natal décadas después. Así, pues, comenzaron a brotar en el inventario de trabajos investigaciones basadas en la recuperación de la memoria a partir de la fotografía familiar histórica.

\section{Imagen y memoria con familias}

Para el tercer grupo de trabajo se intervino con familias descendientes de inmigrantes italianos el siglo XIX en México.

Como muchas otras en el continente y en nuestro propio país, la población de Chipilo de Francisco Javier Mina, en el estado de Puebla, es producto de la inmigración italiana de finales del siglo XIX. Las anteriores migraciones fueron derivadas de hambrunas, heladas y diversos sucesos político-económicos propios de la época. Casos diversos en México, Argentina, Brasil, Estados Unidos, por mencionar algunos países, se encuentran documentados $\mathrm{y}$, al menos, identificados por los círculos académicos relacionados con dichas temáticas.

Sin embargo, la particularidad de Chipilo y su población se basa en los diversos elementos de continuidad cultural que presenta el pueblo con sus orígenes decimonónicos, y quizá anteriores a esta época. Entre los elementos que destacan se encuentra el uso cotidiano de la lengua véneto, las fiestas tradicionales como la conmemoración de la Vecchia Befana, los juegos tradicionales como el rigoletto ${ }^{12}$ y las bochas, la comida tradicional del Véneto y otras cosas más que han sido abordadas en otro trabajo de investigación nuestro.

Para el trabajo de imagen y memoria con familia chipileñas se atendió una necesidad expresada por los propios pobladores en torno a su percepción de pérdida de identidad por parte de los jóvenes, así como el desapego al cuidado de los espacios comunes y cierta falta de respeto hacia

\footnotetext{
12 El rigoletto es un juego tradicional que se desarrolla en el tiempo ritual de la pascua católica y que consiste en rodar huevos de gallina, cocidos y adornados, por una teja en desnivel sobre el suelo. Suele jugarse en familia y entre familias, en donde los huevos son rodados para tocarse y "chocar" al recorrer la pendiente de la teja. Se lanza un huevo por turno. Es una tradición de los habitantes de Chipilo, en Francisco Javier Mina, municipio de San Gregorio Atzompa, Puebla, México.
} 


\section{Revista Iberoamericana \\ de las Ciencias Sociales y Humanísticas}

ISSN: $2395-7972$

las costumbre anteriores. Todo lo anterior mencionado en voz de sus pobladores; de ninguna manera representa nuestra percepción de los jóvenes chipileños.

Con base en lo anterior, se propuso un trabajo de recuperación de la memoria a partir de la preservación de los álbumes fotográficos familiares, en donde se visitó algunas familias, se les explicó el trabajo que se realiza en el LUIM de la BUAP y las estrategias de conservación, digitalización y preservación que desarrollamos para el estudio de la memoria de la vida cotidiana en nuestra región latinoamericana.

La primera recepción de la propuesta fue complicada, ya que muchas personas identifican con valor histórico y social solo a las fotografías más antiguas, aquellas de "los bisabuelos" y los "padres fundadores" y todos los materiales asociados al periodo fundacional y que son tan codiciados por investigadores de diversas áreas del conocimiento, que "les han visitado hasta el cansancio", "se han llevado los materiales" y "nunca han devuelto los trabajos de investigación a la comunidad".

Con este imaginario en mente, basado en ciertas experiencias realmente decepcionantes y otras reconstruidas con cierta exageración por el imaginario colectivo, nos centramos en explicar en reuniones familiares la importancia que tiene para nosotros la fotografía de registro y la comprensión de la diversidad de elementos socioculturales presentes en la vida cotidiana, basándonos en las recomendaciones de la Unesco (1992) y la Convención para la Salvaguardia del Patrimonio Cultural Inmaterial (Unesco, 2003). Con base en lo anterior compartimos nuestra visión de que las fotografías de hoy serán la historia del mañana, con lo que se logró sortear el prejuicio ya descrito.

Una vez estando todos en el mismo canal de comunicación, las familias accedieron a colaborar con sus álbumes familiares, aquellos que retratan la cotidianidad del siglo XX, y accedieron a participar siempre y cuando solo el interés sea en esas fotografías, y no en las "joyas históricas que ya no se muestran más". Varias personas manifestaron no entender qué relevancia tendría estudiar o recuperar en colectivo las fotos de la vida cotidiana, de los niños jugando, de las vacaciones, de las fiestas familiares, de las cosas que solo reflejan modas viejas y recuerdos para los abuelos. También es justo mencionar que diversas personas atesoran los álbumes familiares pero solo por los recuerdos ligados a la niñez propia o la de los hijos, sin que se les atribuya relevancia social. 
Revista Iberoamericana

de las Ciencias Sociales y Humanísticas

ISSN: $2395-7972$

Figura 5. Testimonio fotográfico del trabajo realizado con familias descendientes de inmigrantes italianos el siglo XIX en México

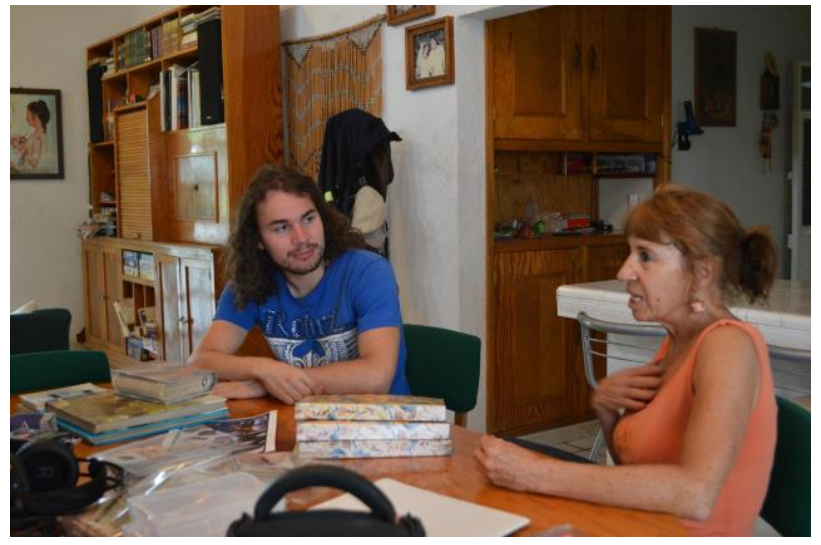

Fuente: Vázquez (2017d)

Figura 6. Testimonio fotográfico del trabajo realizado con familias descendientes de inmigrantes italianos el siglo XIX en México

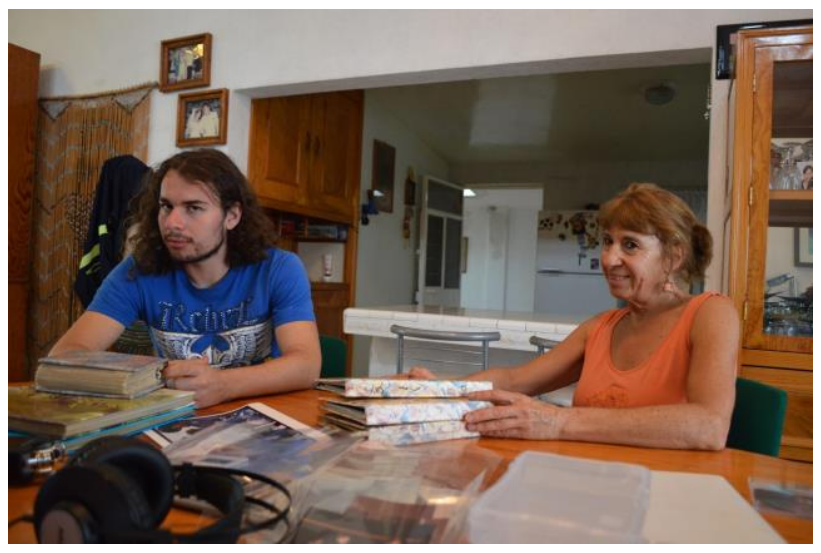

Fuente: Vázquez (2017d) 


\section{Revista Iberoamericana}

de las Ciencias Sociales y Humanísticas

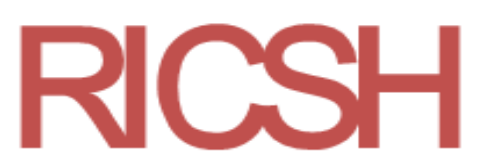

ISSN: $2395-7972$

\section{Conclusiones}

Con base en los tres grupos trabajados se puede llegar a las siguientes reflexiones:

El trabajo con los menores fue sumamente gratificante, pues se observó la importancia de la percepción de la imagen en general, y la fotográfica en específico. Se puede decir que el conocimiento de los procesos de registro y elaboración fotográfica ayudan a ralentizar los procesos de pensamiento tan acelerados de la época actual y permiten al individuo reflexionar sobre su entorno y su pertenencia, en un mundo lleno de estímulos visuales propios y ajenos. Aunado a lo anterior, la planeación que requiere un número limitado de imágenes, como en el caso de las películas que usamos de 12 y 24 exposiciones, obligaron al menor a realizar un proyecto de creación y organización obligatorio para no desperdiciar las tomas posibles.

Pese a que el trabajo fue muy gratificante, se encontraron diversos errores realizados en el taller, que se han corregido en actividades posteriores. Por una parte, no es posible abarcar en una misma sesión los elementos de reflexión sobre la construcción de la imagen fotográfica y su proceso fisicoquímico al mismo tiempo que la fabricación del objeto de producción fotográfica. El estímulo por el trabajo manual y la expectativa del producto final puede ser tan grande en los niños y niñas que resulta altamente probable que el aprendizaje teórico en torno a la fotografía sea opacado. Otro elemento importante identificado es que la realización de la cámara estenopeica de bajo costo puede ser sustituida por cámaras reutilizables impresas en 3D, como actualmente se está implementando. De esta forma se garantiza la reflexión a partir de la construcción de narrativas visuales y la planeación que requiere, en lugar de la elaboración de la manualidad en sí misma.

Para el caso de trabajo con los jóvenes universitarios, formar especialistas interesados en la investigación social a partir de la imagen y la memoria trajo resultados inesperados. Las tesis, ponencias y publicaciones desarrolladas sobre dichas temáticas por los mismos estudiantes son testimonio de ello.

Respecto a las conclusiones del trabajo con las familias en Chipilo, se resalta la reapropiación que las familias hicieron a partir de las sesiones de discusión y los materiales digitales. En muchos casos la gente se asombró al conocer nuestro parecer sobre diversas actividades que a ellos les resultaban muy ordinarias, y que a la luz de la reflexión sociocultural se mostraban como elementos dignos de la preservación y continuidad bajo la figura de Patrimonio Cultural Inmaterial de la Unesco (2003).

Otro elemento digno de señalar es la sorpresa de los jóvenes al conocer la historia de objetos y espacios del pueblo, que simbólicamente les pertenecen al haber sido construidos o traídos por 


\section{Revista Iberoamericana \\ de las Ciencias Sociales y Humanísticas}

ISSN: $2395-7972$

sus abuelos y abuelas. Por ejemplo, un joven comenzó a defender una pared de una escuela que otros jóvenes intentaron vandalizar con pintura en aerosol diciéndoles: "No te pases, no puedes pintar esa barda, la construyó mi abuelo con sus propias manos". O los diversos casos que se constataron en los que las personas de diversas generaciones de las familias con las que se trabajó comenzaron a compartir a través de las redes sociales las fotografías digitalizadas con parientes del mismo pueblo, o con aquellos que habían migrado en años anteriores o décadas pasadas. Verdaderos círculos de discusión y recuperación de la memoria comenzaron a surgir de manera "autógena". Otro caso digno de destacar es el de una persona que mandó a hacer "libros" de fin de año para regalar a los parientes, con las fotografías digitalizadas en el laboratorio. La alta resolución de la digitalización permitió realizar diversos trabajos impresos de gran calidad, además de los usos en la red que no requieren tanta resolución para difundirse.

En suma, se pueden enlistar, desde la óptica de la innovación social, los siguientes objetivos alcanzados:

a) Recuperación de espacios urbanos a partir de los métodos y técnicas de análisis semiótico de la fotografía y la reconstrucción de la historia oral, utilizando a la fotografía química como centro de los trabajos de la investigación.

b) Uso de recursos de bajo costo para promover la reflexión de procesos colectivos e identitarios vinculados al reconocimiento social.

c) Fortalecimiento de las relaciones e interacciones socioculturales positivas que, estando debilitadas, producen violencia social.

Como dato curioso, ninguno de los usos aplicados o de difusión derivados de los tres proyectos reconoce el trabajo realizado desde el LUIM en la BUAP. Por otra parte, una de las políticas del LUIM es no generar marcas de agua a los objetos digitales creados en este espacio, pues las metas se basan en el poder detonar la recuperación de la memoria y la recuperación del tejido social. Lograrlo es suficiente reconocimiento para dicho laboratorio. Ya sea desde la historia oral, la comunicación para el cambio social o la perspectiva de la fotografía como documento social, se sabe que los diversos materiales y trabajos que se realizan no le pertenecen a nadie en específico, sino a toda la humanidad y el objetivo en torno a dichos procesos es que todas y todos puedan acceder los materiales de manera libre, gratuita y con alta calidad. La meta concreta para lograrlo es consolidar un repositorio digital en la BUAP que permita el acceso y la libre descarga de las imágenes en alta resolución, con su catalogación profesional, para libre uso. Que un niño de seis años pueda utilizar imágenes de su región para su monografía escolar, que un investigador 


\section{Revista Iberoamericana}

de las Ciencias Sociales y

Humanísticas

ISSN: $2395-7972$

consolidado las pueda utilizar para su libro de investigación especializada, es la principal motivación. Y que las personas hagan retroalimentación de los vacíos que tenemos en torno a la información y catalogación de dichas imágenes es el mayor reto. Por las dificultades técnicas, costos, equipos, materiales y demás vicisitudes, la BUAP ha respaldado de manera generosa y contundente los proyectos del LUIM, por lo que nuestro compromiso con la eficiencia en torno a los usos y aplicaciones de la imagen y la memoria para la innovación social, desde la universidad pública, se ha convertido en un estilo de vida.

\section{Referencias}

Barra, P. A. (2005). El Manual de normas catalográficas del Sistema Nacional de Fototecas. México: Instituto Nacional de Antropología e Historia.

Casanova, R. (2005). De vistas y retratos: la construcción de un repertorio fotográfico en México, 1839-1890. En Imaginarios y fotografía en México 1839-1970. México: Conaculta-INAHSistema Nacional de Fototecas / Fundación Telefónica / Conaculta-Cenart / Centro de la Imagen / Lunwerg editores.

Canales, C. (2005). Cronología”, en Imaginarios y Fotografía en México 1839-170. En Imaginarios y fotografía en México 1839-1970. México: Conaculta-INAH-Sistema Nacional de Fototecas / Fundación Telefónica / Conaculta-Cenart / Centro de la Imagen / Lunwerg editores.

Corona, S. (2007). Fotografías de indígenas. En Comunicación y Política. Versión 20. México: Universidad Autónoma Metropolitana Unidad Xochimilco.

Debroise, O. (2005). Fuga mexicana, un recorrido por la fotografía en México. Barcelona, España: Editorial Gustavo Gili.

Del Castillo, A. (2005). La historia de la fotografía en México, 1890-1920. La diversidad de los usos de la imagen. En Imaginarios y Fotografía en México 1839-1970. México: ConacultaINAH-Sistema Nacional de Fototecas / Fundación Telefónica / Conaculta-Cenart / Centro de la Imagen / Lunwerg editores.

González, L. (2007). Fotografías que cuentan historias. México: Instituto Nacional de Antropología e Historia / Lumen / Consejo Nacional para la Cultura y las Artes.

Imagen olvidada. (s. f.). ¿Que es la fotografía estenopeica? Recuperado de https://imagenolvidada.jimdo.com/que-es-la-fotograf\%C3\%ADa-estenopeica/. 
Revista Iberoamericana

de las Ciencias Sociales y

Humanísticas

ISSN: 2395 - 7972

Monroy, R. (2005). Del medio tono al alto contraste: la fotografía mexicana de 1920 a 1940. En Imaginarios y fotografía en México 1839-1970. México: Conaculta-INAH-Sistema Nacional de Fototecas / Fundación Telefónica / Conaculta-Cenart / Centro de la Imagen / Lunwerg editores.

Morales, A. (2005). La Venus se fue de juerga. Ámbitos de la fotografía mexicana 1940-1970. En Imaginarios y fotografía en México 1839-1970. México: Conaculta-INAH-Sistema Nacional de Fototecas / Fundación Telefónica / Conaculta-Cenart / Centro de la Imagen / Lunwerg editores.

Morris, C. (1985). Fundamentos de la teoría de los signos. Barcelona: Paidós.

Organización de las Naciones Unidas para la Educación, la Ciencia y la Cultura [Unesco]. (1992). Programa Memoria del Mundo (MoW): Preservando el patrimonio documental. Oficina Regional de Educación para América Latina y el Caribe. Recuperado de http://www.unesco.org/new/es/santiago/communication-information/memory-of-theworld-programme-preservation-of-documentary-heritage/.

Organización de las Naciones Unidas para la Educación, la Ciencia y la Cultura [Unesco]. (2003). Convención para la Salvaguardia del Patrimonio Cultural Inmaterial. Oficina Regional de Educación para América Latina y el Caribe. Recuperado de http://www.unesco.org/new/es/santiago/culture/intangible-heritage/convention-intangiblecultural-heritage/20.

Peirce, S. (1974). La ciencia de la semiótica. Buenos Aires Argentina: Nueva Visión Buenos Aires.

Pericot, J. (2002). Mostrar para decir. La imagen en contexto. Barcelona: Universidad Autónoma de Barcelona.

Ramírez, E. ( 2001). Fotografía indígena e indigenista. Revista de Ciencias, (60), 119-125.

Sánchez, F. J. (2006). La máquina etnográfica. Reflexiones sobre fotografía y antropología visual. Contraluz, 3(3).

Valdez, J. C. (2001). Glosarios de términos empleados en conservación fotográfica. México: Cuadernos del Sistema Nacional de Fototecas.

Vázquez, V. (2003). Más allá del recuerdo: Análisis de imágenes fotográficas realizadas por los totonaco de San Pedro Petlacotla, Puebla. (tesis de maestría). Universidad Nacional Autónoma de México, Ciudad de México, México. 
Revista lberoamericana

de las Ciencias Sociales y Humanísticas

ISSN: 2395 - 7972

Vázquez, V. (2015a). Diversas miradas: La imagen fotográfica y su análisis para la investigación social. En Solano, A. R. y León, I. (coords.), Imagen, Memoria y Patrimonio (pp. 67-84). México: El Errante Editor/BUAP.

Vázquez, V. (2015b). Estudiantes de licenciatura en comunicación en el Seminario de Fotografía e Imagen para la Investigación Social. (fotografía). Lugar: BUAP. Puebla, México.

Vázquez, V. (2015c). Estudiantes de licenciatura en comunicación en el Seminario de Fotografía e Imagen para la Investigación Social. (fotografía). Lugar: BUAP. Puebla, México.

Vázquez, V. (2017a). Más allá del recuerdo: el uso de la fotografía en el pueblo totonaco. En Báez, M. y Álvarez, G. (coords.), Olhar In(com)formado: Teorias e práticas da Antropologia Visual (pp. 322-360). Goiânia, Brasil: Editora da Imprensa Universitári.

Vázquez, V. (2017b). Enseñando a elaborar la cámara estenopeica en el internado. (fotografía). Lugar: Internado Julian Hinojosa. Puebla, México.

Vázquez, V. (2017c). Rostro de una niña elaborando una cámara estenopeica. (fotografía). Lugar: Internado Julian Hinojosa. Puebla, México.

Vázquez, V. (2017d). Testimonio fotográfico del trabajo realizado con familias descendientes de inmigrantes italianos el siglo XIX en México. (fotografía). Lugar: Chipilo. Puebla, México.

Vázquez, V. (2017f). Testimonio fotográfico del trabajo realizado con familias descendientes de inmigrantes italianos el siglo XIX en México. (fotografía). Lugar: Chipilo. Puebla, México.

Villela, S. (1998). Fotógrafos viajeros y la antropología mexicana. Antropología e Imagen. Revista Cuicuilco, 5(13). 
Revista Iberoamericana

de las Ciencias Sociales y

Humanísticas

\begin{tabular}{|c|c|}
\hline Rol de Contribución & Autor (es) \\
\hline Conceptualización & Iván G. Deance B. y T. / Verónica Vázquez Valdés（igual) \\
\hline Metodología & Iván G. Deance B. y T. / Verónica Vázquez Valdés (igual) \\
\hline Software & N/A \\
\hline Validación & Mariano Báez Landa (que apoya) \\
\hline Análisis Formal & Iván G. Deance B. y T. / Verónica Vázquez Valdés (igual) \\
\hline Investigación & Iván G. Deance B. y T. / Verónica Vázquez Valdés (igual) \\
\hline Recursos & Laboratorio Universitario de Imagen y Memoria - BUAP \\
\hline Curación de datos & N/A \\
\hline $\begin{array}{l}\text { Escritura - Preparación del } \\
\text { borrador original }\end{array}$ & Iván G. Deance B. y T. / Verónica Vázquez Valdés (igual) \\
\hline $\begin{array}{l}\text { Escritura - Revisión y } \\
\text { edición }\end{array}$ & Iván G. Deance B. y T. / Verónica Vázquez Valdés (igual) \\
\hline Visualización & Iván G. Deance B. y T. / Verónica Vázquez Valdés (igual) \\
\hline Supervisión & Iván G. Deance B. y T. / Verónica Vázquez Valdés (igual) \\
\hline $\begin{array}{l}\text { Administración } \\
\text { Proyectos }\end{array}$ & Iván G. Deance B. y T. / Verónica Vázquez Valdés (igual) \\
\hline $\begin{array}{l}\text { Adquisición de fondos «que } \\
\text { apoya» }\end{array}$ & $\begin{array}{l}\text { Facultad de Ciencias de la Comunicación / Vicerrectoría de } \\
\text { Docencia BUAP (que apoya) }\end{array}$ \\
\hline
\end{tabular}

